significant differences were found in the Fres of children who had previously been diagnosed with asthma by a doctor compared to non asthmatics ( $p=0.015)$; and those with atopy and wheeze compared to those with no atopic wheeze $(\mathrm{p}=0.015)$ (Abstract P79 Figure 1).

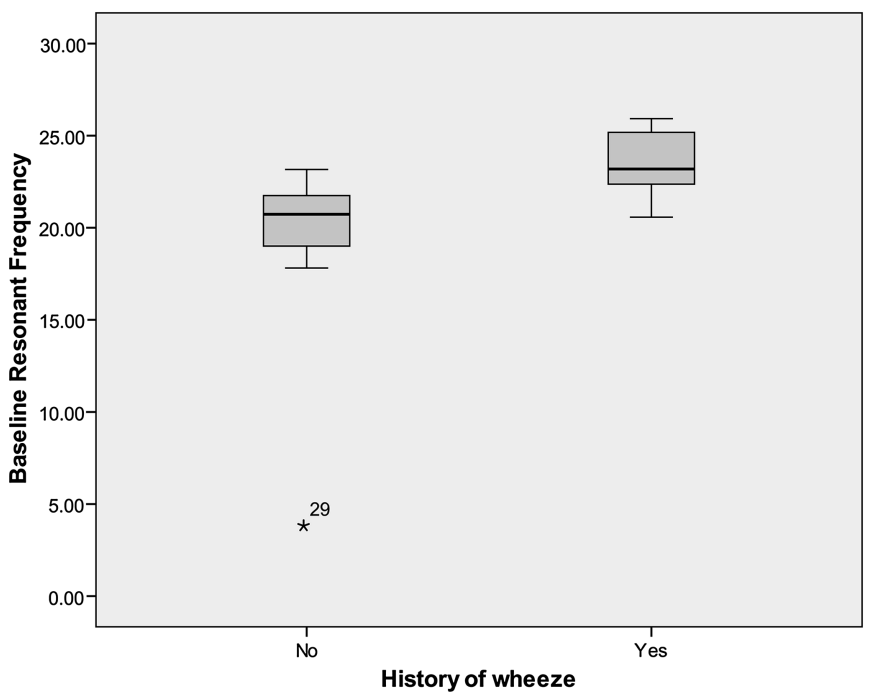

Abstract P79 Figure 1 The differences in resonant frequency between preschool children with a history of wheeze and those without a history of wheeze.

Discussion IOS yields high quality lung function data in most children over 3.5 years age. The technique is able to detect group differences related to wheezing tendency in this age group, and may be a useful clinical tool for use in young children over 3.5 years.

\section{P80 PRE-OPERATIVE ASSESSMENT OF CHILDREN UNDERGOING SCOLIOSIS SURGERY}

doi:10.1136/thx.2010.150979.31

${ }^{1} \mathrm{~A}$ L Ross Russell, ${ }^{2} \mathrm{~S}$ Charlton, ${ }^{3} \mathrm{E}$ R Mooney, ${ }^{3} \mathrm{C}$ Ward, ${ }^{4} \mathrm{R}$ I Ross Russell. ${ }^{1}$ School of Clinical Medicine, John Radcliffe Hospital, Oxford, UK; ${ }^{2}$ Department of Orthopaedics, Addenbrooke's Hospital, Cambridge, UK; ${ }^{3}$ School of Clinical Medicine, Addenbrooke's Hospital, Cambridge, UK; ${ }^{4}$ Department of Paediatrics, Addenbrooke's Hospital, Cambridge, UK

Introduction Historically, assessment of operative risk in children prior to scoliosis surgery has been largely based on pre-operative lung function testing. Children having scoliosis surgery suffer from a wide range of conditions and many are unable to perform lung function testing. Furthermore, the risk of post-operative ventilation is decreasing suggesting better predictors may be needed. We currently evaluate all such patients, using assessment of airway competency, cough strength, and muscle bulk in estimating the risk of requiring post-operative ventilation. Our data suggest that lung function testing is no longer a good predictor of outcome in this group of patients.

Methods We retrospectively reviewed the records of 97 patients who have undergone scoliosis surgery between 2004 and 2010. Pulmonary function testing (PFT) was attempted wherever possible. Patients were clinically assessed prior to surgery, and an estimated risk of post-operative ventilation made. Comparison of each method (PFT and clinical assessment) against a primary outcome of requirement for post-operative ventilation, and secondary outcomes of PICU/HDU and hospital length of stay.

Results PFTwas successful in 68/97 (70\%) of our patients. One child had an FVC $<40 \%$ predicted and three children had FVC $40-50 \%$ predicted. None of these children required ventilation post- operatively. Of the 14 patients who required post-operative ventilation, pulmonary function testing was only possible for four (FVC range $59 \%-74 \%$ predicted). The remaining 10 who needed ventilation were unable to perform PFT. Clinical assessment of risk was highly accurate in predicting the number of children requiring postoperative ventilation in all groups (Abstract P80 Table 1).

\section{Abstract P80 Table 1}

\begin{tabular}{lllll}
\hline $\begin{array}{l}\text { Predicted } \\
\text { risk level }\end{array}$ & No in group & $\begin{array}{l}\text { Predicted } \\
\text { number } \\
\text { ventilated }\end{array}$ & $\begin{array}{l}\text { Actual } \\
\text { number } \\
\text { ventilated }\end{array}$ & $\begin{array}{l}\text { Hospital LoS } \\
\text { (days-median, range) }\end{array}$ \\
\hline Low $(<10 \%)$ & 62 & 3.2 & 3 & $7(4-16)$ \\
Medium (10-30\%) & 20 & 3.1 & 5 & $9(3-21)$ \\
High $(>30 \%)$ & 13 & 6.3 & 5 & $10(3-22)$ \\
\hline
\end{tabular}

Conclusions The group of patients who are most likely to require post-operative ventilation are poor candidates for pulmonary function testing. To assess these children we need to take account of other factors which are important for their respiratory function post-operatively. Clinical assessment of risk can be highly accurate in predicting the need for ventilation following scoliosis surgery.

\section{P81 THE CHANGING INCIDENCE OF PAEDIATRIC EMPYEMA IN NE ENGLAND 2006-2010}

doi:10.1136/thx.2010.150979.32

${ }^{1} \mathrm{M}$ F Thomas, ${ }^{2} \mathrm{C}$ Simmister, ${ }^{1} \mathrm{~S}$ P Rushton, ${ }^{1} \mathrm{D}$ A Spencer. ${ }^{1}$ Newcastle University, Newcastle-Upon-Tyne, UK; ${ }^{2}$ Newcastle-upon-Tyne NHS Foundation Trust, Newcastleupon-Tyne, UK

Introduction and objectives The incidence of empyema has been increasing in children. We investigated trends in the incidence of empyema cases over the time period 2006-2010 in relation to temperature, rainfall and the introduction of the pneumococcal vaccine using regression analysis.

Methods All admissions with ICD-10 codes J86.0 and J86.9 coding for pyothorax with/without fistula from 1st January 2006 until 31st May 2010 were collated. A generalised least squares (GLS) modelling technique was employed to investigate trends in child cases in relation to local average monthly maximum temperature and monthly rainfall. The timing of the introduction of the PCV-7 vaccine was included as a co-variate.

Results 183 cases of paediatric empyema were identified. There was a negative relationship between number of cases of childhood empyema and average maximum temperature in the month of admission ( $t=-2.24, p>0.00)$. Introduction of the PCV-7 vaccine was associated with a reduction in cases $(t=-5.00, p=0.02)$. There was no significant relationship between the number of cases and average monthly rainfall. There was no significant evidence of autocorrelation for this model suggesting that the number of cases each month were independent of the number in the preceding or following month. Fitted values from the model and the observed trend in cases are shown in Abstract P81 Figure 1. The number of cases appears to be inversely related to temperature variation across the year. The R-squared of the final model was 0.36, whilst the $\mathrm{R}$-squared for model without the vaccine was 0.30 , suggesting that $6 \%$ of the variation in cases could be explained by the introduction of the vaccine.

Conclusions Mean maximum temperature in the month of admission appears to be a significant predictor of cases of empyema and correlates with the cyclical pattern of cases. Introduction of PCV-7 vaccine was associated with a reduction in the number of cases which may be related to a combination of direct and indirect vaccine effects secondary to improved herd immunity. Further work is 
required to establish whether this finding is generic across the UK and the underlying mechanisms driving this phenomenon.
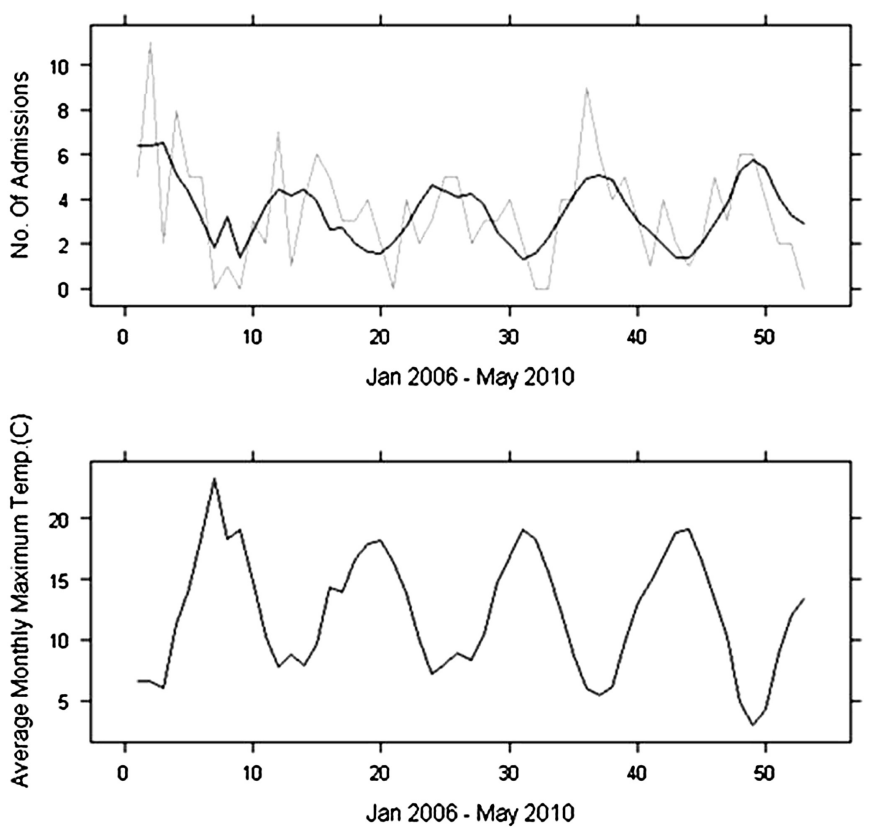

Abstract P81 Figure 1 Variation in monthly admissions of children with empyema and variation in mean monthly maximum temperature from January 2006-May 2010. 1st plot: Grey line-observed number of admissions, Black line-admissions predicted by model.

\section{P82 WHAT IS THE ROLE OF CHEST COMPUTED TOMOGRAPHY IN CHILDREN WITH PARAPNEUMONIC EFFUSION?}

doi:10.1136/thx.2010.150979.33

A Parmar, G Peek, R Firmin, H Pandya, E Gaillard. University Hospitals Leicester NHS Trust, Leicester, England

Introduction The incidence of parapneumonic effusion in children has been rising in the UK since the mid 1990s (1). There is anecdotal evidence that the number of complicated cases with more severe illness may be increasing. This is frequently due to severe underlying, often necrotic pneumonia, caused by unusual organisms (2), pulmonary abscesses or bronchopleural fistulas. Chest ultrasound does not reliably identify these processes and CT scanning is the investigation of choice. However, there has been little research in the use of chest CT in children with parapneumonic effusion and its use remains controversial.

Aims To evaluate the usefulness of chest CT in children with parapneumonic effusion.

Methods We retrospectively reviewed the medical notes and imaging of all children admitted between January 2004 and December 2009 with a diagnosis of parapneumonic effusion to the University Hospitals of Leicester NHS Trust.

Results A total of 183 children were identified. Of this number, 51 children underwent CT scanning. The main indications for chest CT were as follows: slow/no response to IV antibiotic treatment (25\%), failed attempt at chest drainage without urokinase (24\%) and acute critical clinical deterioration (16\%). Other indications included failure of chest drainage with urokinase, failure of surgical intervention or investigation for other pathology. A range of pathological findings were identified with CT. $38 \%$ of the CT scans identified collapse consolidation. Other pathology was also identified that was not apparent on ultrasound scan. $4 \%$ identified pulmonary abscess,
$4 \%$ identified areas of lung necrosis, $4 \%$ identified broncho-pleural fistula and $6 \%$ identified cavitating pneumonias.

Conclusion (1) A chest CT is useful in children with a complicated parapneumonic effusion to detect lung pathology not readily detected with chest ultrasound. (2) A small number of children have a pulmonary abscess complicating the parapneumonic effusion. (3) Further research is needed to establish the role and timing of chest CT scanning in children with infective pleural disease.

\section{REFERENCES}

1. BTS Standards of Care Committee. BTS guidelines for the management of pleural infection in children. Thorax 2005:60(Suppl I):i1-21.

2. Thomas B, Pugalenthi A, Chilvers M. Pleuropulmonary complications of PVL-positive Staphylococcus aureus infection in children. Acta Paediatr 2009;98:1372-5.

\section{Respiratory education and training issues P83 VALIDATION OF A NOVEL PORCINE-RESIN THORAX MODEL FOR CHEST DRAIN INSERTION TRAINING}

doi:10.1136/thx.2010.150979.34

T R Naicker, E A Hughes, D T McLeod. Sandwell General Hospital, Birmingham, UK

Objective Our poster at the 2009 winter BTS meeting described the Chest drain training module for CMT1 and CMT2 trainees in West Midlands Deanery. We have proceeded further to formally validate our novel Porcine-Resin thorax model for Chest drain insertion training by assessing the face, content, and construct validity of the model.

Methods We recruited 82 doctors who work in General Medicine and Allied Specialties in Hospitals across West Midlands Deanery in UK. They were further divided into three groups as novice, intermediate and expert depending on the number of chest drains they had performed previously. During the study, they were asked to insert a chest drain using seldinger technique in the Porcine-Resin thorax model and their performance was recorded and marked anonymously using checklist scoring system. We developed the model using porcine ribs mounted on a resin cast of human thorax. All participants completed a questionnaire regarding the realism of the simulator after they completed $2 \mathrm{~h}$ of training and updated their skills using the model. In addition, the intermediate and expert groups also have given their views regarding the appropriateness of the simulator for training and assessment purposes.

Results The expert group performed better than the intermediate group ( $p<0.0001)$, which in turn performed better than the novices $(p<0.0001)$.The expert group rated the overall realism of the simulator at 5.2, Intermediate group at 5.4 and the Novice group at 5.26 on a seven-point Likert scale. No statistically significant differences were observed between the group mean scores.

Conclusion Through this study we have demonstrated that our Porcine-Resin thorax model was able to discriminate between different levels of expertise (construct validity) in seldinger chest drain insertion. All the three groups have agreed that this offers a realistic experience in chest drain insertion training for residents (face validity) and in addition the experts believe that this model can also be used competency assessments.

\begin{tabular}{lllll}
\hline Group & N & Mean score & SD & Cl (95\%) \\
\hline Novice $<5$ procedures & 30 & 11.3 & 4.54 & 9.6 to 12.9 \\
Intermediate 5 to 25 & 30 & 19.3 & 4.5 & 17.9 to 21.8 \\
Expert $>$ 25 procedures & 22 & 33.95 & 7.27 & 30.5 to 37.3 \\
\hline
\end{tabular}

\section{REFERENCE}

1. Gallagher AG, Ritter EM, Satava RM. Fundamental principles of validation, and reliability: rigorous science for the assessment of surgical education and training. Surg Endosc 2003:17:1525-9. 